\title{
Quadratic Engel Curves and Consumer Demand
}

\author{
James Banks; Richard Blundell; Arthur Lewbel
}

The Review of Economics and Statistics, Vol. 79, No. 4. (Nov., 1997), pp. 527-539.

Stable URL:

http://links.jstor.org/sici?sici=0034-6535\%28199711\%2979\%3A4\%3C527\%3AQECACD\%3E2.0.CO\%3B2-Z

The Review of Economics and Statistics is currently published by The MIT Press.

Your use of the JSTOR archive indicates your acceptance of JSTOR's Terms and Conditions of Use, available at

http://www.jstor.org/about/terms.html. JSTOR's Terms and Conditions of Use provides, in part, that unless you have obtained prior permission, you may not download an entire issue of a journal or multiple copies of articles, and you may use content in the JSTOR archive only for your personal, non-commercial use.

Please contact the publisher regarding any further use of this work. Publisher contact information may be obtained at http://www.jstor.org/journals/mitpress.html.

Each copy of any part of a JSTOR transmission must contain the same copyright notice that appears on the screen or printed page of such transmission.

The JSTOR Archive is a trusted digital repository providing for long-term preservation and access to leading academic journals and scholarly literature from around the world. The Archive is supported by libraries, scholarly societies, publishers, and foundations. It is an initiative of JSTOR, a not-for-profit organization with a mission to help the scholarly community take advantage of advances in technology. For more information regarding JSTOR, please contact support@ jstor.org. 


\title{
The Review of Economics and Statistics
}

VoL. LXXIX

NOVEMBER 1997

NUMBER 4

\section{QUADRATIC ENGEL CURVES AND CONSUMER DEMAND}

\author{
James Banks, Richard Blundell, and Arthur Lewbel*
}

\begin{abstract}
This paper presents a model of consumer demand that is consistent with the observed expenditure patterns of individual consumers in a long time series of expenditure surveys and is also able to provide a detailed welfare analysis of shifts in relative prices. A nonparametric analysis of consumer expenditure patterns suggests that Engel curves require quadratic terms in the logarithm of expenditure. While popular models of demand such as the Translog or the Almost Ideal Demand Systems do allow flexible price responses within a theoretically coherent structure, they have expenditure share Engel curves that are linear in the logarithm of total expenditure. We derive the complete class of integrable quadratic logarithmic expenditure share systems. A specification from this class is estimated on a large pooled data set of U.K. households. Models that fail to account for Engel curvature are found to generate important distortions in the patterns of welfare losses associated with a tax increase.
\end{abstract}

\section{Introduction}

$\mathrm{D}^{\mathrm{s}}$ EMAND models play an important role in the evaluation of indirect tax policy reform. We argue that for many commodities, standard empirical demand models do not provide an accurate picture of observed behavior across income groups. Our aim is to develop a demand model that can match patterns of observed consumer behavior while being consistent with consumer theory and thereby allowing welfare analysis.

The distributional analysis of commodity tax policy requires the accurate specification of both price and income effects. Crude utility-based demand models such as the linear expenditure system, however, impose strong and unwarranted restrictions on price elasticities (Deaton (1974)). Recognition of this spawned a large literature, first on flexible demand systems and later on semiparametric and nonparametric specifications of demands. Except for the estimation of Engel curves, these nonparametric methods are generally series rather than kernel based (see Barnett and Jonas (1983) or Gallant and Souza (1991)) because of the

Received for publication June 27, 1995. Revision accepted for publication October 1, 1996.

* Institute for Fiscal Studies. Also University College London, University College London, and Brandeis University, respectively.

This is a revised version of our earlier paper, "Quadratic Engel Curves, Tax Reform and Welfare Measurement." We would like to thank two anonymous referees as well as Martin Browning, Alan Duncan, Angus Deaton, Terrence Gorman, Costas Meghir, Jean-Marc Robin, James Stock, Thomas Stoker, Guglielmo Weber, and seminar participants at Brown, Harvard, INSEE, Nuffield, Northwestern, Stanford, and LSE for helpful comments. Financing for this research, provided by the ESRC Research Centre for the Micro Economic Analysis of Fiscal Policy at IFS and the NSF under Project SES-9011806, is gratefully acknowledged. Thanks are also due to the Department of Employment for providing the FES data used in this study. The usual disclaimer applies. difficulty of imposing utility-derived structure (such as Slutsky symmetry) on kernel estimators.

Since incomes vary considerably across individuals and income elasticities vary across goods, the income effect for individuals at different points in the income distribution must be fully captured in order for a demand model to predict responses to tax reform usefully. Indeed, the study of the relationship between commodity expenditure and income (the Engel curve) has been at the center of applied microeconomic welfare analysis since the early studies of Engel (1895), Working (1943), and Leser (1963). But a complete description of consumer behavior sufficient for welfare analysis requires a specification of both Engel curve and relative price effects consistent with utility maximization. An important contribution of the Muellbauer (1976), Deaton and Muellbauer (1980), and Jorgenson et al. (1982) studies was to place the Working-Leser Engel curve specification within integrable consumer theory.

For many commodities, however, there is increasing evidence that the Working-Leser form underlying these specifications does not provide an accurate picture of individual behavior. A series of empirical Engel curve studies indicates that further terms in income are required for some, but not all, expenditure share equations (see, for example, Atkinson et al. (1990), Bierens and Pott-Buter (1987), Blundell et al. (1993), Hausman, et al. (1995), Härdle and Jerison (1988), Hildenbrand (1994), and Lewbel (1991)). For welfare analysis we will show that if some commodities require these extra terms while others do not (as we find in our empirical analysis), then parsimony, coupled with utility theory, restricts the nonlinear term to being a quadratic in log income.

We derive a new class of demand systems that have log income as the leading term in an expenditure share model and additional higher order income terms. This preserves the flexibility of the empirical Engel curve findings while permitting consistency with utility theory and is shown to provide a practical specification for demands across many commodities, allowing flexible relative price effects. We show that the coefficients of the higher order income terms in these models must be price dependent and that these higher order terms have to include a quadratic logarithmic term. The demands generated by this class are shown to be rank 3 which, as proved in Gorman (1981), is the maximum possible rank for any demand system that is linear in functions of income. The quadratic logarithmic class nests 
both the Almost Ideal (AI) model of Deaton and Muellbauer and the exactly aggregable Translog model of Jorgenson et al. (1982). Unlike these demand models, however, the quadratic logarithmic model permits goods to be luxuries at some income levels and necessities at others. The empirical analysis we report suggests that this is an important feature.

Using data from the U.K. Family Expenditure Survey (FES), under a variety of alternative parametric and nonparametric estimation techniques, we are able to strongly reject the Working-Leser form for some commodities, while for others, in particular food, Engel curves do look very close to being linear in log income. This analysis confirms that share equations quadratic in the logarithm of total expenditure can provide a good approximation to the Engel relationship in the raw microdata.

It is interesting to note that Rothbarth and Engel equivalence scales of the sort discussed in Deaton and Muellbauer (1986) implicitly assume that Engel curves are monotonic in utility, and hence in total expenditures. The Engel curvature found in our data violates this assumption. For example, Rothbarth scales may use expenditures on alcohol or adult clothing to measure welfare. Our quadratic Engel curves for these goods invalidate such techniques since both rich and poor households could have the same expenditure on these commodities.

Having established the Engel curve behavior, a complete demand model is estimated on a pooled FES data set using data from 1970 to 1986 . This model produces a datacoherent and plausible description of consumer behavior. The specific form we propose- the Quadratic Almost Ideal Demand System (QUAIDS) - is constructed so as to nest the AI model and have leading terms that are linear in log income while including the empirically necessary rank 3 quadratic term. Regularity conditions for utility maximization, such as Slutsky symmetry, can be imposed on our model and are not statistically rejected. Regularity constraints involving inequalities cannot hold globally for any demand system such as ours, which allows some Engel curves to be Working-Leser, because at sufficiently high expenditure levels a budget share that is linear must go outside the permitted zero-to-one range. ${ }^{1}$ Despite this, negative semidefiniteness of the Slutsky matrix is found to hold empirically in the majority of the sample, with the exceptions being the very high income households.

More specifically, let $x$ equal deflated income, that is, income divided by a price index. One convenient feature of the AI model is that the coefficients of $\ln x$ in the budget share equations are constants. Our theorem 1 shows that any parsimonious rank 3 extension must be quadratic in $\ln x$. Given this, it would be convenient ${ }^{2}$ if a rank 3 specification could be constructed in which the coefficients of both $\ln x$

\footnotetext{
${ }^{1}$ Some globally regular demand systems do exist (Barnett and Jonas (1983) and Cooper and McLaren (1996), for example), but these are all examples of fractional demand systems, and none with rank higher than 2 have been implemented empirically.

${ }^{2}$ It was shown by Blundell et al. (1993) to be empirically plausible.
}

and $(\ln x)^{2}$ were constants. We find that a surprising implication of utility maximization is that constant coefficients are not possible in such models-the coefficients of $(\ln x)^{2}$ must vary with prices. The QUAIDS model we propose makes this required price dependence as simple as possible.

The layout of the paper is as follows. Section II contains our assessment of the Engel curve relationship. In section III the theoretical results are presented, and the restrictions placed on the model by consumer demand theory are derived. Section IV presents estimates of relative price and income effects for our QUAIDS model of demand, which relaxes these restrictions. The restrictions are rejected, as are linear logarithmic preferences. In section V we illustrate the importance of our results for the welfare evaluation of indirect tax reform with two specific reforms which highlight differences in consumer behavior across goods. A brief summary and concluding comments are presented in section VI.

\section{Assessing the Shape of the Engel Curve Relationship}

Given the importance of the Engel relationship, we begin our analysis by providing a nonparametric description of the Working-Leser model. In this model each expenditure share is defined over the logarithm of deflated income or total expenditure. The evidence in the raw expenditure data from the U.K. FES for a quadratic extension to this linear relationship can be seen clearly from the preliminary data analysis presented below. Although we make comparisons across household types, in order to place emphasis on the shape of the Engel curve we use a relatively homogeneous subsample taken from the 1980-1982 surveys for which there are two married adults with the husband employed and who live in London and the South East.

This choice reflects the need to preserve homogeneity of composition since we have good reason to believe that the shape of Engel curves is likely to vary with labor market status and region (see Browning and Meghir (1991) and Blundell et al. (1993)). It also reflects our desire to pin down the shape of the Engel curve before moving to the timeseries information on relative price movements in our repeated cross sections. ${ }^{3}$

Figure 1 presents nonparametric kernel regressions, quadratic polynomial regressions, and pointwise confidence intervals for the nonparametric Engel curves of our five commodity groups in a three-year period in the middle of our sample. In all kernel regressions we use the Gaussian kernel with a mean integrated squared-error optimal smoothing parameter (see Härdle (1990)). ${ }^{4}$ Although the linear formulation appears to provide a reasonable approximation for the food share curve, for some groups, in particular

\footnotetext{
${ }^{3}$ In addition we trim any observations that lie outside three standard deviations of the mean on either the logarithm of total expenditure or any of the five commodity expenditure shares.

${ }^{4}$ All computations were carried out using Gauss and the Gauss-based interactive kernel regression package NP-REG (see Duncan and Jones (1992)).
} 
Figure 1A.-NonParametric ENGEL CuRve for Food Shares

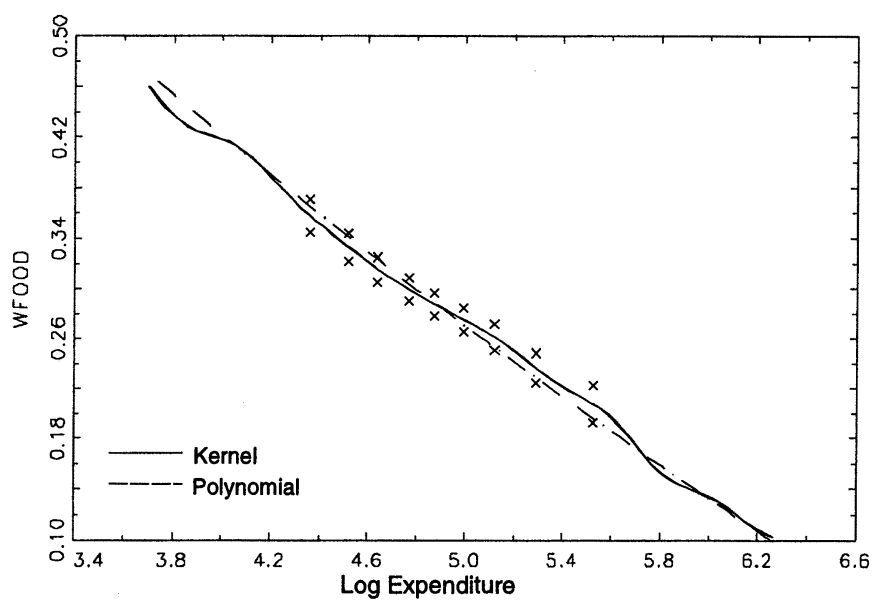

Figure 1C.-NonParametric Engel Curve for Clothing Shares

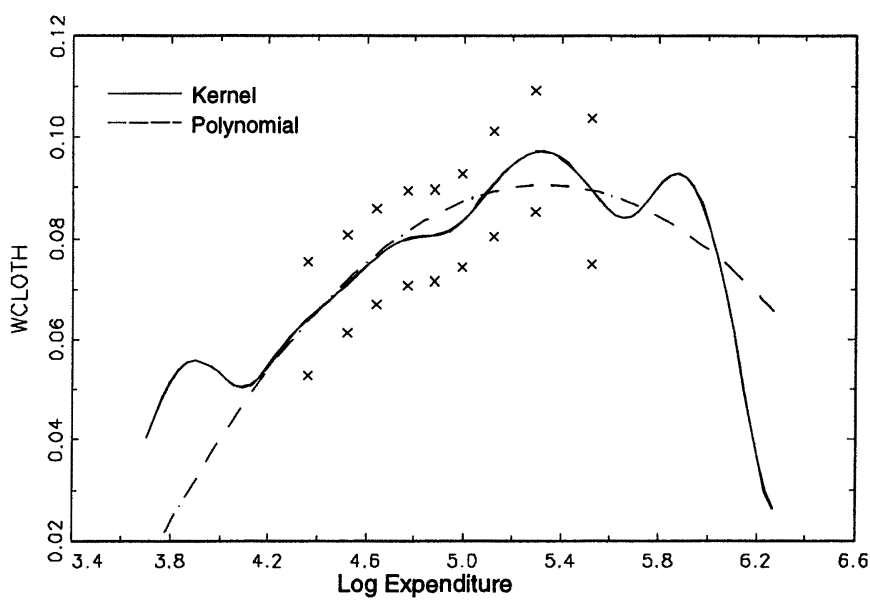

Figure 1E.-NonParametric ENGEL CuRve For OTHER GoOdS

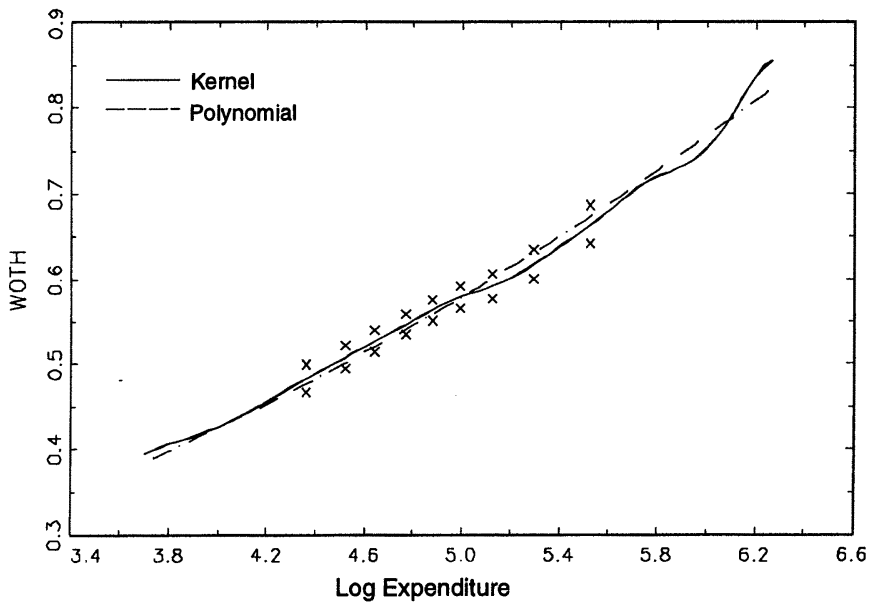

alcohol and clothing, distinct nonlinear behavior is evident, at least in the raw data.

It is interesting to focus on a comparison with the simple second-order polynomial fit. Some guidance to the reliability of the quadratic approximation can be drawn from the pointwise confidence intervals (evaluated at decile points)
Figure 1B.-Nonparametric Engel Curve for Domestic Fuel Shares

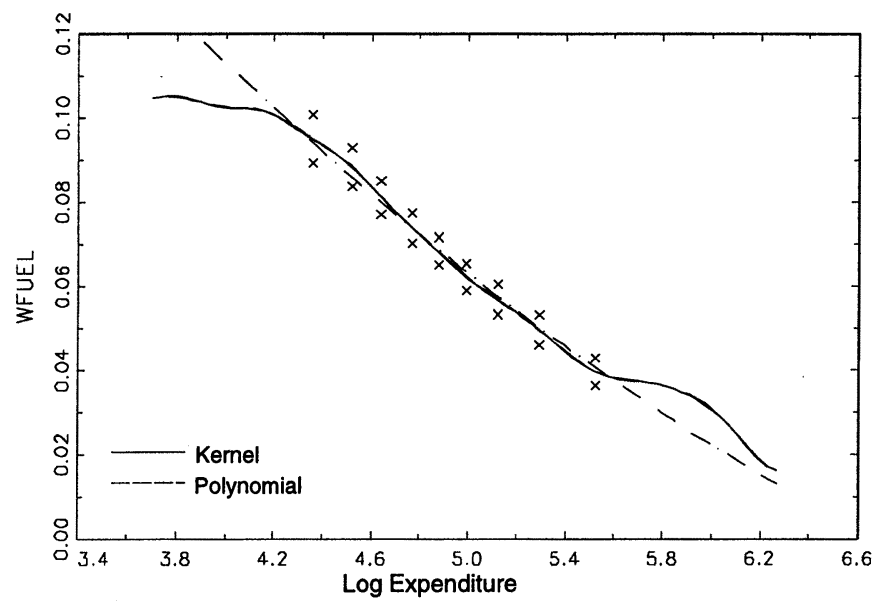

Figure 1D.-NoNPaRAMETRIC ENGEl CURVE For AlcoHol SHARES

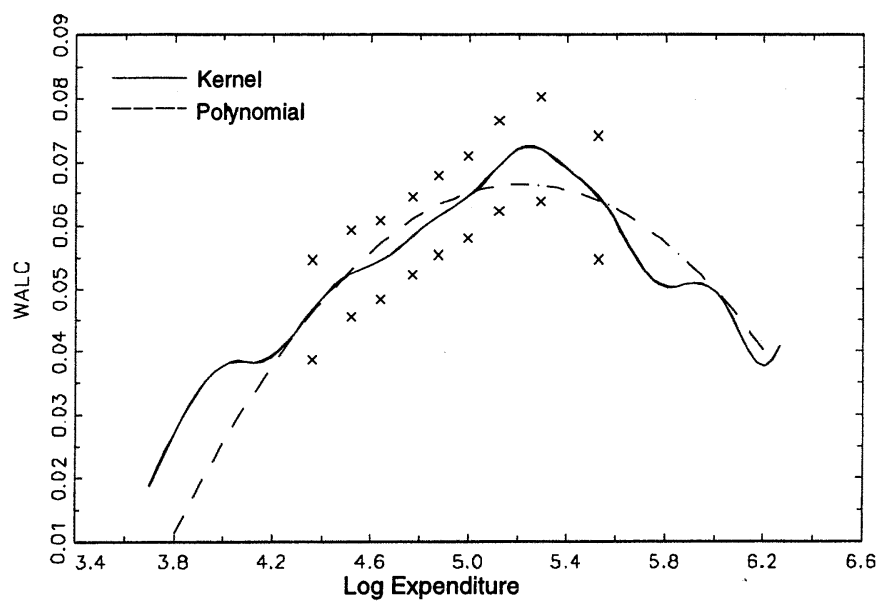

shown in the graphs. It is only where the data are sparse and the confidence bands relatively wide that the paths diverge. This appears to be the case for all five commodity groups across the span of the data period.

The need for higher order terms in the Engel curve relationship is also evident from the rank test results 
Table 1.-Rank Tests for FES Data 1980-1982

\begin{tabular}{ccccccc}
\hline & \multirow{2}{*}{ Test } & Distribution & \multicolumn{2}{c}{ Gill and Lewbel (1992) } & & \multicolumn{2}{c}{ Cragg and Donald (1995) } \\
\cline { 6 - 7 } & Function & $\chi^{2}$ Statistic & $p$-Value & & $\chi^{2}$ Statistic & $p$-Value \\
\hline$r=1$ & 4 & 13849.170 & 0.000 & & 448.461 & 0.000 \\
$r=2$ & 3 & 10.232 & 0.016 & & 31.360 & 0.000 \\
$r=3$ & 2 & 0.004 & 0.997 & & 7.784 & 0.100 \\
\hline
\end{tabular}

presented in table 1 . This test examines the maximum rank of the coefficient matrix on a general set of income functions, as in Lewbel (1991). The first test uses the lower-diagonal-upper (LDU) Gaussian elimination decomposition as a basis for a nonparametric test (see Gill and Lewbel (1992)). The second test is an alternative improved distance measure related test proposed by Cragg and Donald (1995), which imposes the restriction that budget shares sum to 1 . Our results refer to the 1980-1982 subset of data. Table 1 provides values for a sequence of asymptotic $\chi^{2}$ tests against the alternative that the rank is greater than $r$. There is a strong suggestion that a rank 3 relationship is required, as would be the case in our second-order polynomial.

Detailed results (available from the authors) indicate stability in these overall patterns across time and across alternative bandwidth choices for the nonparametric regressions. It is perhaps more important to note that the overall picture is maintained for other demographic groups. For example, figure 2a shows shifts in the Engel curve for food as the household size varies. The overall shape is little affected by variations in the choice of kernel or smoothing parameter. Indeed, the behavior in the tails of the kernel regressions in figure 1 reflects low density in the data and is made more stable in figure $2 \mathrm{a}$ by the adoption of the computationally more expensive adaptive kernel.

These raw data analyses should be viewed with caution for a number of reasons. Most obviously one would expect additional covariates. This point is largely accounted for by the selection of a homogeneous subsample. Possibly of more importance are assumptions on the stochastic specification underlying the kernel regressions. The explanatory variable is the logarithm of (deflated) total expenditure on the sum of the five consumption categories. This is likely to be endogenous. Our first line of analysis therefore is to assess to what extent the rejection of linearity can be attributed to one of these stochastic problems. To do this we follow both nonparametric and parametric approaches.

The ordinary least-squares (OLS) regression estimates corresponding to the quadratic approximation to the kernel regressions are given in table 2 . As one might expect, they imply similar conclusions as the plots we have already discussed. Quadratic terms are significant for clothing, alcohol, and other goods, but linearity appears to be sufficient to explain expenditure shares on food and fuel. To allow for the possibility of endogeneity, we instrument $\log$ expenditure and its square by log income and its square. One way of computing this estimator is by the inclusion of the two reduced-form residuals in an extended OLS regression (see Holly (1982)). This "Wu-Hausman" technique has the advantage of directly testing exogeneity through the joint significance of the two residual terms. Exogeneity of $\log$ expenditure is strongly rejected, but the residuals on the reduced form for the square of log expenditure (presented in the penultimate row of table 2) are not jointly significant. This suggests that including the reduced-form residual on $\log$ expenditure alone is sufficient to control for endogeneity. Joint normality of $\log$ expenditure and the Engel curve disturbances would be sufficient to guarantee this result. In figure $2 \mathrm{~b}$ we show the closeness to normality of the $\ln x$ distribution in our data.

Table 2 also presents results for the quadratic model under this correction for endogeneity. These estimates differ from the OLS results but display the same overall patterns. As a final check on our specification we include higher-order terms in log expenditure, which are presented in the final row of table 2 . These are also jointly insignificant.

As a descriptive alternative to this instrumental variable procedure, we show a more nonparametric picture of the robustness of our Engel curve results. For this we consider

Figure 2A.-Engel Curves for Food, By Family Type

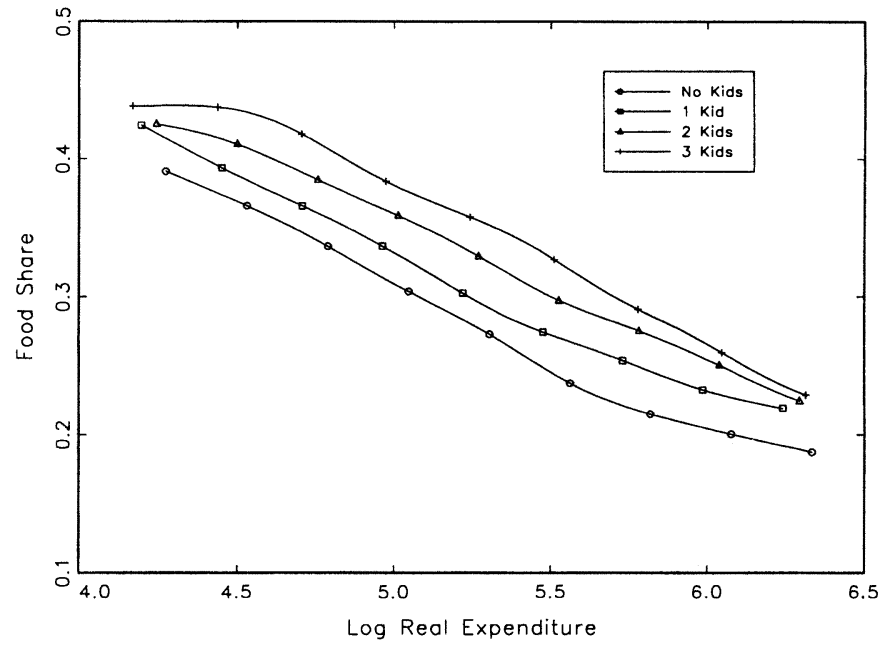

Figure 2B.-The Distribution of Log Non-Durable EXPENDITURE

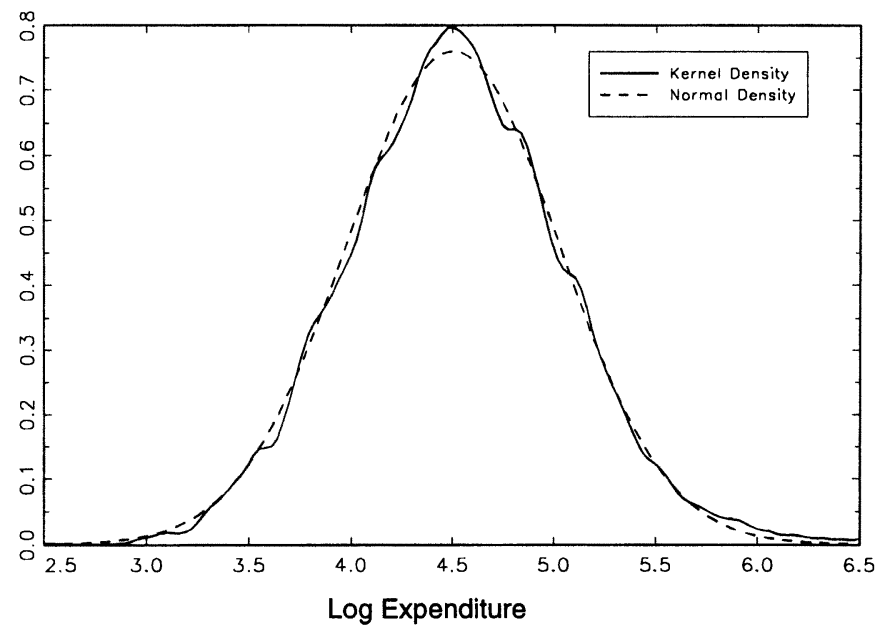


Table 2.--Engel Curve Parameters, FES Data 1980-1982: Share Equations

\begin{tabular}{|c|c|c|c|c|c|}
\hline & Food & Fuel & Clothing & Alcohol & Other \\
\hline \multicolumn{6}{|c|}{$O L S$} \\
\hline $\ln x$ & $-0.1785(0.0840)$ & $-0.0600(0.0318)$ & $0.2759(0.0524)$ & $0.2229(0.0524)$ & $-0.2602(0.1298)$ \\
\hline $\ln x^{2}$ & $0.0039(0.0089)$ & $0.0016(0.0033)$ & $-0.0237(0.0056)$ & $-0.0237(0.0056)$ & $0.0448(0.0140)$ \\
\hline \multicolumn{6}{|c|}{ Wu-Hausman } \\
\hline $\ln x$ & $-0.1593(0.0940)$ & $-0.0498(0.0334)$ & $0.2749(0.0920)$ & $0.2286(0.0617)$ & $-0.2943(0.1424)$ \\
\hline $\ln x^{2}$ & $0.0046(0.0100)$ & $0.0020(0.0036)$ & $-0.0267(0.0098)$ & $-0.0235(0.0066)$ & $0.0436(0.0152)$ \\
\hline$v_{1}$ & $-0.0321(0.0165)$ & $-0.0170(0.0059)$ & $0.0017(0.0160)$ & $-0.0096(0.0108)$ & $0.0570(0.0251)$ \\
\hline \multicolumn{6}{|c|}{ Alternative Specifications } \\
\hline$\tau_{2}$ & $-0.0780(0.0524)$ & $-0.0590(0.0212)$ & $0.0520(0.0499)$ & $0.0129(0.0341)$ & $0.0721(0.0779)$ \\
\hline $\ln x^{3}$ & $-0.0135(0.0060)$ & $0.0023(0.0022)$ & $-0.0035(0.0058)$ & $0.0127(0.0039)$ & $0.0020(0.0090)$ \\
\hline $\begin{array}{l}\text { Notes: (1) St } \\
\text { (2) The estim } \\
\text { (3) All share } \\
\text { (4) } v_{1} \text { is the } r \\
\text { (5) The alter } \\
\text { f the logarithn }\end{array}$ & $\begin{array}{l}\text { s are in parentheses. } \\
\text { table are the restricted estin } \\
\text { so contain age and age squ } \\
\text { a residual from the predicti } \\
\text { ications presented report th } \\
\text { The final line presents par }\end{array}$ & here the instrument set c & $\begin{array}{l}\text { In expenditure, } v_{1} \text {, alone i } \\
\text { s, spouses' employment stat } \\
\text { and age squared of both ad } \\
\text { sitivity of the model. } v_{2} \text { is th } \\
\text { was jointly insignificant ac }\end{array}$ & $\begin{array}{l}\text { dummies, and a constant. } \\
\text { ne, seasonal dummies, rela } \\
\text { om the reduced form for (ln }\end{array}$ & $\begin{array}{l}\text { price index, and a constant. } \\
\text { he instrument includes the square }\end{array}$ \\
\hline
\end{tabular}

the fitted value $\widehat{\ln x}$ based on our vector of instruments. Under the null hypothesis that the budget shares are at least approximately Working-Leser, a kernel regression of $w_{i}$ on $\widehat{\ln x}$ would look linear even if $\ln x$ were endogenous. Under the null, the asymptotic distribution of the kernel regression is not affected by the estimation error in $\widehat{\ln x}$, because the convergence rate of $\widehat{\ln x}$ is root $N$, which is faster than that of the kernel regression. Figure 3 shows these regressions for clothing and alcohol, assuming the reduced form for $\widehat{\ln x}$ is linear. The kernel regressions look highly nonlinear, indicating that dependence between $\ln x$ and the share equation errors is not responsible for the observed curvature in the Engel curves of figure 1.

In summary, these preliminary data investigations suggest two distinct features of our expenditure data. For certain goods such as food, the linear logarithmic expenditure share model provides a robust description of behavior. Second, for certain other goods the linear model needs to be supplemented by some other, possibly quadratic, term in log expenditure.

\section{Utility Maximization and the Shape of Engel Curves}

Over time and in the presence of indirect tax changes, relative prices as well as real incomes change. The analysis of these changes requires a demand system that is able to accommodate the Engel curve shapes uncovered in the previous section while allowing for data-coherent relative price responses. The evidence of section II suggests Engel curves that have leading terms linear in the logarithm of income and additional higher order terms in income. Our aim in this section is to consider utility functions that are consistent with such Engel curves. In the empirical estimation of section IV we check whether the resulting demand system is consistent with the price, income, and expenditure share data.

Demands having expenditure shares that are linear in log total expenditure (hereafter referred to as $\ln m$ ) alone have been called Price-Independent Generalized Logarithmic (PIGLOG) by Muellbauer (1976), and arise from indirect utility functions that are themselves linear in $\ln m$. Examples of PIGLOG demands include Deaton and Muellbauer's (1980) AI demand system and Jorgenson et al.'s (1982) translog model. Since the empirical Engel curves for some goods (i.e., food) look linear in $\ln m$, we consider generalizations of PIGLOG preferences.

\section{A. Extensions of PIGLOG Preferences}

The simplest general form of demands consistent with the empirical evidence on Engel curves is

$$
w_{i}=A_{i}(\mathbf{p})+B_{i}(\mathbf{p}) \ln x+C_{i}(\mathbf{p}) g(x)
$$

for goods $i=1, \ldots, N$, where $\mathbf{p}$ is the $N$-vector of prices, $x=m / a(\mathbf{p})$, and $A_{i}(\mathbf{p}), B_{i}(\mathbf{p}), C_{i}(\mathbf{p})$, and $g(x)$ are differentiable functions.

Equation (1) says that expenditure shares are linear in log income and in another smooth function of income, $g(x)$. The $C_{i}(\mathbf{p}) g(x)$ term allows for the nonlinearities apparent in figure 1 for clothing and alcohol, whereas the Engel curves that look like PIGLOG have $C_{i}(\mathbf{p})$ near zero.

Lewbel (1991) defines the rank of any demand system to be the dimension of the space spanned by its Engel curves. The rank of equation system (1) equals the rank of the $N \times 3$ matrix of Engel curve coefficients, having rows $\left[A_{i}(\mathbf{p}): B_{i}\right.$ (p): $C_{i}(\mathbf{p})$ ] for goods $i$. This matrix has three columns, so 3 is the maximum possible rank of equation system (1). Exactly aggregable demand systems are defined as demand systems that are linear in functions of $m$. Gorman (1981) proved that the maximum possible rank of any exactly aggregable demand system (with any number of terms) is 3 . The empirical evidence on Engel curves indicates that observed demands are rank 3 . These theoretical and empirical results together suggest that there would be little or no gain in adding additional terms of the form $D_{i}(\mathbf{p}) h(x)$ to equation (1). 
Figure 3a.-Robust Testing for Linear Engel Curves: Alcohol Shares

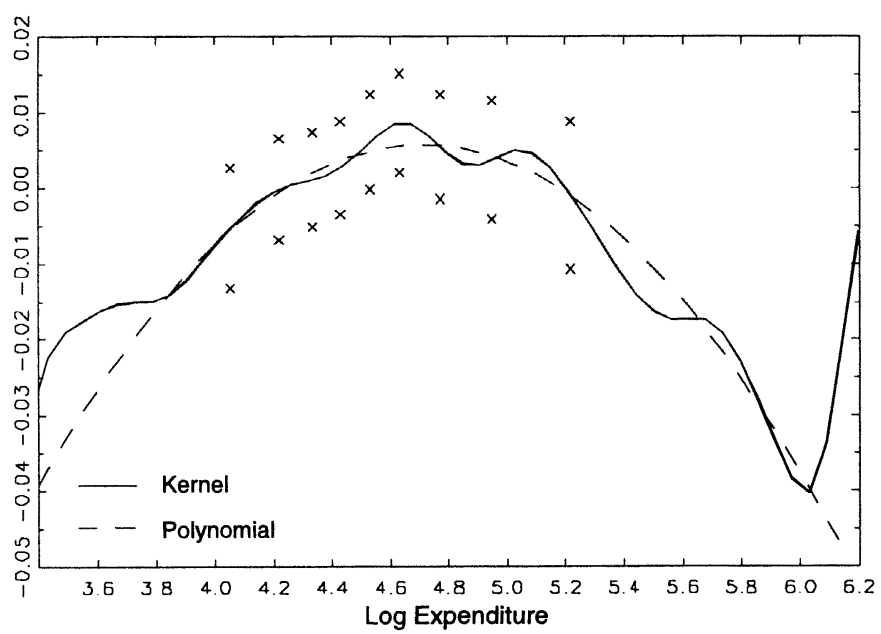

Figure 3B.-Robust Testing for Linear Engel Curves: Clothing Shares

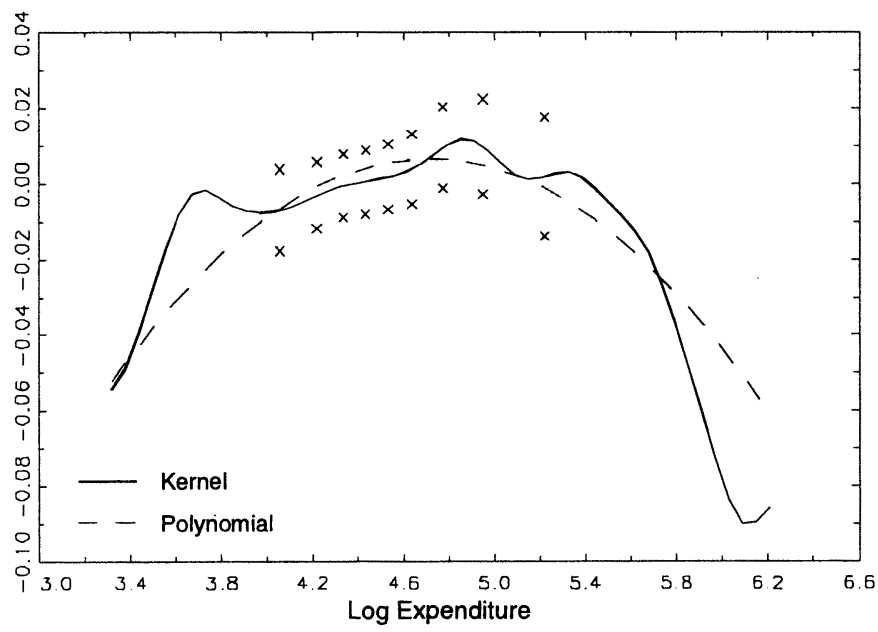

The following theorem characterizes demand systems that are consistent with equation (1).

THEOREM 1: All exactly aggregable demand systems in the form of equation (1) that are derived from utility maximization either have

$$
C_{i}(\mathbf{p})=d(\mathbf{p}) B_{i}(\mathbf{p})
$$

for some function $d(\boldsymbol{p})$ (so the rank is less than 3 ), or they are rank 3 quadratic logarithmic budget share systems having indirect utility functions of the form

$$
\ln V=\left\{\left[\frac{\ln m-\ln a(\mathbf{p})}{b(\mathbf{p})}\right]^{-1}+\lambda(\mathbf{p})\right\}^{-1}
$$

where the term $[\ln m-\ln a(\boldsymbol{p})] / b(\boldsymbol{p})$ is the indirect utility function of a PIGLOG demand system (i.e., a system with budget shares linear in log total expenditure), and the extra term $\lambda$ is a differentiable, homogeneous function of degree zero of prices $\boldsymbol{p}$.

For a proof see appendix A.

Notice that when $\lambda(\mathbf{p})$ is independent of prices, the indirect utility function reduces to a form observationally equivalent to the PIGLOG class, which includes the AI model and the translog model of Jorgenson et al. By Roy's identity the budget shares are given by

$$
w_{i}=\frac{\partial \ln a(\mathbf{p})}{\partial \ln p_{i}}+\frac{\partial \ln b(\mathbf{p})}{\partial \ln p_{i}}(\ln x)+\frac{\partial \lambda}{\partial \ln p_{i}} \frac{1}{b(\mathbf{p})}(\ln x)^{2}
$$

which are quadratic in $\ln x=\ln m-\ln a(\mathbf{p})$. It can be seen that $A_{i}$ in equation (1) corresponds to the $i$ th $\ln \mathbf{p}$ derivative of $\ln a(\mathbf{p})$; similarly for $B_{i}$ and $C_{i}$. This is precisely the Engel curve relationship fitted on the FES data in the previous section.

The empirical evidence on Engel curves appears to rule out condition (2), since some goods, such as food, have budget shares nearly linear in $\ln x$ whereas others display strong nonlinearities. Equation (2) would also require that the ratio of the coefficient on $(\ln x)^{2}$ to the coefficient on $\ln x$ be the same for all goods, which is clearly violated by the estimates in table 2 . As a result theorem 1 suggests that budget shares of the form of equation (4) should be considered.

Theorem 1 makes equation (1) demands satisfy homogeneity and symmetry. Utility maximization also imposes inequality constraints on the functions comprising equations (2) and (3), resulting from concavity conditions. Our strategy will be to estimate the demand systems without imposing these inequality constraints and then check that our estimates of the required inequalities are in the range of our data.

COROLLARY 1: Utility-derived demand systems in the form of equation (1) can be constructed for any regular function $g(x)$, but all rank 3 exactly aggregable utility-derived demand systems in the form of equation (1) have $g(x)=$ $(\ln x)^{2}$.

To prove corollary 1, let $G(x)=-\int[x \ln x+x g(x)]^{-1} d x$. Then the indirect utility function $V=G(m / a(\mathbf{p}))+b(\mathbf{p})$ yields rank 2 demands in the form of equation (1), as can be verified directly using Roy's identity. This method can be used to construct rank 2 utility-derived equation (1) systems for any function $g$ (subject only to restrictions required for cost function concavity and existence of the integral defining $G$, which is what is meant here by regularity). Given theorem 1, equations (3) and (4) prove the rank 3 case of corollary 1 .

Corollary 1 shows that confining attention to exactly aggregable, utility-derived equation (1) forms does not by 
itself force the quadratic logarithmic specification. It is the additional requirement that demands be rank 3 that forces $g(x)$ to equal $(\ln x)^{2}$.

Since rank 3 forces $g(x)=(\ln x)^{2}$, budget shares are quadratic in $\ln x=\ln m-\ln a(\mathbf{p})$ and therefore are quadratic in $\ln m$ itself. Having proved this much, the actual characterization of rank 3 quadratic logarithmic demands given in equation (3) can be readily derived from analogous constructions in Howe et al. (1979) or van Daal and Merkies (1989). An additional contribution of theorem 1 is equation (2), which shows exactly how the coefficients collapse to rank 2 when the utility function does not have the quadratic logarithmic form of equation (3).

Fortunately every empirical Engel curve analyzed in section II does look either linear or quadratic in $\ln x$, and hence the observed Engel curves appear to be rank 3 and do not violate the restrictions required for utility maximization that are revealed in theorem 1 .

The following corollary provides another surprising implication of utility maximization that is revealed by theorem 1 .

COROLlary 2: No rank 3 exactly aggregable utilityderived equation system (1) exists that has both $B_{i}(\boldsymbol{p})$ and $C_{i}(\boldsymbol{p})$ independent of prices.

To prove the corollary, for each commodity $i$, set the expressions for $B_{i}(\mathbf{p})$ and $C_{i}(\mathbf{p})$ implied by equation (4) equal to constants. The only solution to the resulting expressions for $b(\mathbf{p})$ and $\lambda(\mathbf{p})$ are $b(\mathbf{p})=\Pi p_{i}^{\beta_{i}}$ and $\lambda(\mathbf{p})$ proportional to $b(\mathbf{p})$, which makes equation (2) hold and therefore causes the system to collapse to rank 2 .

The AI demand system has the form of equation (1), with each $B_{i}$ constant (that is, independent of prices) and every $C_{i}=0$. The natural extension of the AI system would be to let both $B_{i}$ and $C_{i}$ be constants, with $C_{i}$ nonzero for commodities being nonlinear in $x$ budget shares, such as alcohol and clothing. For example, Blundell et al. (1993) obtain good fits estimating models in the form of equation (1), with $B_{i}$ and $C_{i}$ constant. They take $A_{i}$ and $B_{i}$ to be of the AI system form, that is,

$$
w_{i}=\alpha_{i}+\gamma_{i}^{\prime} \ln \mathbf{p}+\sum_{j=1}^{2} \beta_{i j}(\ln x)^{j}+\text { error }_{i} .
$$

Unfortunately, by corollary $2, B_{i}$ and $C_{i}$ cannot both be constants for all commodities $i$ while maintaining rank 3 , as is empirically required. For demand systems in the form of equation (5), theorem 1 and corollary 2 show that utility maximization rather unexpectedly forces

$$
w_{i}=\alpha_{i}+\gamma_{i}^{\prime} \ln \mathbf{p}+\beta_{i l}\left[\ln x+\epsilon(\ln x)^{2}\right]+\text { error }_{i}
$$

where $\epsilon$ is some constant, requiring that all Engel curves have the same quadratic in $\ln x$ expenditure shares. Figure 1 alone clearly rules out equation (6), so any model that is both theoretically and empirically acceptable must have quadratic coefficients that vary with prices. The QUAIDS specification retains the overall form of the quadratic model in Blundell et al. (1993) but introduces this price dependence in a parsimonious way.

\section{Estimation of Income and Relative Price Effects}

\section{A. A Quadratic Almost Ideal Demand System}

The analysis of the last two sections suggests that the quadratic demand systems in equation (4) provide a datacoherent structure for consumer preferences in the FES data. To construct a simple quadratic logarithmic specification consistent with equation (3), we begin by considering Deaton and Muellbauer's AI demand system. ${ }^{5}$ The AI model has an indirect utility function given by equation (3), but with the $\lambda$ term set to zero. In particular, $\ln a(\mathbf{p})$ has the translog form

$$
\begin{aligned}
\ln a(\mathbf{p})= & \alpha_{0}+\sum_{i=1}^{n} \alpha_{i} \ln p_{i} \\
& +\frac{1}{2} \sum_{i=1}^{n} \sum_{j=1}^{n} \gamma_{i j} \ln p_{i} \ln p_{j}
\end{aligned}
$$

and $b(\mathbf{p})$ is the simple Cobb-Douglas price aggregator defined above,

$$
b(\mathbf{p})=\prod_{i=1}^{n} p_{i}^{\beta_{i}}
$$

The AI model is popular in part because it has budget shares that, conditional on $a(\mathbf{p})$, are linear in $\ln \mathbf{p}$ and $\ln x$, which simplifies estimation. However, the analysis in section II shows that the AI system, being linear in $\ln x$ and rank 2, requires generalization. The results of section II show that a demand model consistent with both the predictions of demand theory and our empirical evidence must be rank 3 and have the form of equations (1) and (3).

Our goal is to construct a system that is as similar as possible to the convenient AI model while allowing for the more general Engel curve shapes discovered in section II. To do so, we define the indirect utility in $V$ by equation (3) with

$$
\lambda(\mathbf{p})=\sum_{i=1}^{n} \lambda_{i} \ln p_{i}, \quad \text { where } \sum_{i} \lambda_{i}=0 .
$$

Equations (3), (7), (8), and (9) together define what we call QUAIDS. By equation (4) the corresponding expenditure

${ }^{5}$ We could equally well work from the translog model of Jorgenson et al. (1982). 
share equation system is

$$
\begin{aligned}
w_{i}= & \alpha_{i}+\sum_{j=1}^{n} \gamma_{i j} \ln p_{j}+\beta_{i} \ln \left[\frac{m}{a(\mathbf{p})}\right] \\
& +\frac{\lambda_{i}}{b(\mathbf{p})}\left\{\ln \left[\frac{m}{a(\mathbf{p})}\right]\right\}^{2}
\end{aligned}
$$

where the impact of demographic and other household characteristics could be allowed to enter all terms. ${ }^{6}$ The QUAIDS model has the income flexibility and rank suggested by the Engel curve analysis of the previous two sections. it has the same degree of price flexibility as the usual AI and translog models, it is as close to linearity in parameters as theorem 1 will permit, it has the AI model nested within it as a special case, and it has as few additional parameters over the AI model as possible, given all these features.

To calculate QUAIDS model elasticities, differentiate equation (10) with respect to $\ln m$ and $\ln p_{j}$, respectively, to obtain

$$
\begin{aligned}
\mu_{i} \equiv & \frac{\partial w_{i}}{\partial \ln m}=\beta_{i}+\frac{2 \lambda_{i}}{b(\mathbf{p})}\left\{\ln \left[\frac{m}{a(\mathbf{p})}\right]\right\} \\
\mu_{i j} \equiv & \frac{\partial w_{i}}{\partial \ln p_{j}}=\gamma_{i j}-\mu_{i}\left(\alpha_{j}+\sum_{k} \gamma_{j k} \ln P_{k}\right) \\
& -\frac{\lambda_{i} \beta_{j}}{b(\mathbf{p})}\left\{\ln \left[\frac{m}{a(\mathbf{p})}\right]\right\}^{2} .
\end{aligned}
$$

The budget elasticities are given by $e_{i}=\mu_{i} / w_{i}+1$, and with a positive $\beta$ and a negative $\lambda$ (as suggested in section II for clothing and alcohol), will be seen to be greater than unity at low levels of expenditure, eventually becoming less than unity as the total expenditure increases and the term in $\lambda_{i}$ becomes more important. Such commodities therefore have the characteristics of luxuries at low levels of total expenditure and necessities at high levels.

The uncompensated price elasticities are given by $e_{i j}^{u}=$ $\mu_{i j} / w_{i}-\delta_{i j}$, where $\delta_{i j}$ is the Kronecker delta. We use the Slutsky equation, $e_{i j}^{c}=e_{i j}^{u}+e_{i} w_{j}$, to calculate the set of compensated elasticities $e_{i j}^{c}$ and assess the symmetry and negativity conditions by examining the matrix with elements $w_{i}\left[e_{i j}^{c}\right]$, which should be symmetric and negative semidefinite in the usual way.

\section{B. Estimating Relative Price and Income Effects}

To estimate this model we take a sample of households from the repeated cross sections of the U.K. FES for the period of 1970-1986, adopting the same sample selection as

\footnotetext{
${ }^{6}$ Note that rebasing prices implies a rescaling of the $\alpha_{0}$ and $\gamma_{i}$ parameters. The demand system and implied welfare measures are invariant to such rebasing.
}

in section II. The selected sample has 4785 observations over 68 quarterly price points, and later price data at the appropriate aggregation are unavailable. We consider the system defined above for the five goods analyzed in section II (food, fuel, clothing, alcohol, and other nondurable nonhousing expenditures), imposing homogeneity by expressing all prices relative to the price of "other" goods.

To deal with the possibility of endogeneity, measurement error, and nonnormality of errors, a generalized method of moments (GMM) estimation procedure is used. The system is nonlinear and estimation follows two stages. In the first stage an iterated moment estimator is adopted, which exploits the conditional linearity of equation (10) given $a(\mathbf{p})$ and $b(\mathbf{p})$. That is, given $a(\mathbf{p})$ and $b(\mathbf{p})$, the system is linear in parameters, and this suggests a natural iterative procedure conditioning on an updated $a(\mathbf{p})$ and $b(\mathbf{p})$ at each iteration. ${ }^{7}$ This technique preserves the adding-up and invariance properties of the system. To derive the symmetry-restricted estimates, the optimum minimum distance estimator was used at the second stage (see Blundell (1988) and Browning and Meghir (1991) for a full description of this technique). Incidentally, if we were to consider a household in the base period when all relative prices are unity, their price index $\ln [a(\mathbf{p})]$ would simply be equal to $\alpha_{0}$, and since we require real expenditure to be positive, then the minimum level of log real expenditure observed in the data places an upper bound on $\ln \left[a\left(\mathbf{p}_{t}\right)\right]$ and therefore $\alpha_{0}$ in the base period. ${ }^{8}$

\section{Empirical Results}

Table 3 presents the symmetry-restricted parameter estimates for our preferred quadratic specification. In line with the evidence presented in section III, we restrict the coefficients on the quadratic terms for the food and fuel equations to be zero. The full unrestricted model estimates are presented in appendix B. Given the homogeneity of our sample, we choose to allow only a limited number of additional factors to influence preferences (i.e., age, seasonal dummies, and a time trend) through $\alpha_{i}$ in equation (10). Households are chosen to be demographically homogeneous which, given the large samples at our disposal, seems a reasonable way to proceed.

Table 3 clearly shows the importance of quadratic terms in real expenditure for clothing and alcohol, as the nonparametric analysis suggested. As we will use the AI model for comparison in the welfare analysis that follows, we report estimates of the corresponding AI specification in appendix B. The diagnostics suggest that higher order price terms are not required and also that linearity in $\ln m$ for food and fuel cannot be rejected. Moreover, in this QUAIDS specification the symmetry restrictions, tested with a $\chi^{2}$ statistic, are not

\footnotetext{
7 The consistency of this procedure and its asymptotic efficiency properties are described in Blundell and Robin (1996).

${ }^{8}$ Our choice of the parameter $\alpha_{0}$ follows the original discussion in Deaton and Muellbauer (1980) and is chosen to be just below the lowest value of $\ln m$ in our data. To check that this did not affect our results, we also chose a grid of values.
} 
Table 3.-Demand System Parameter Estimates and $t$-Ratios

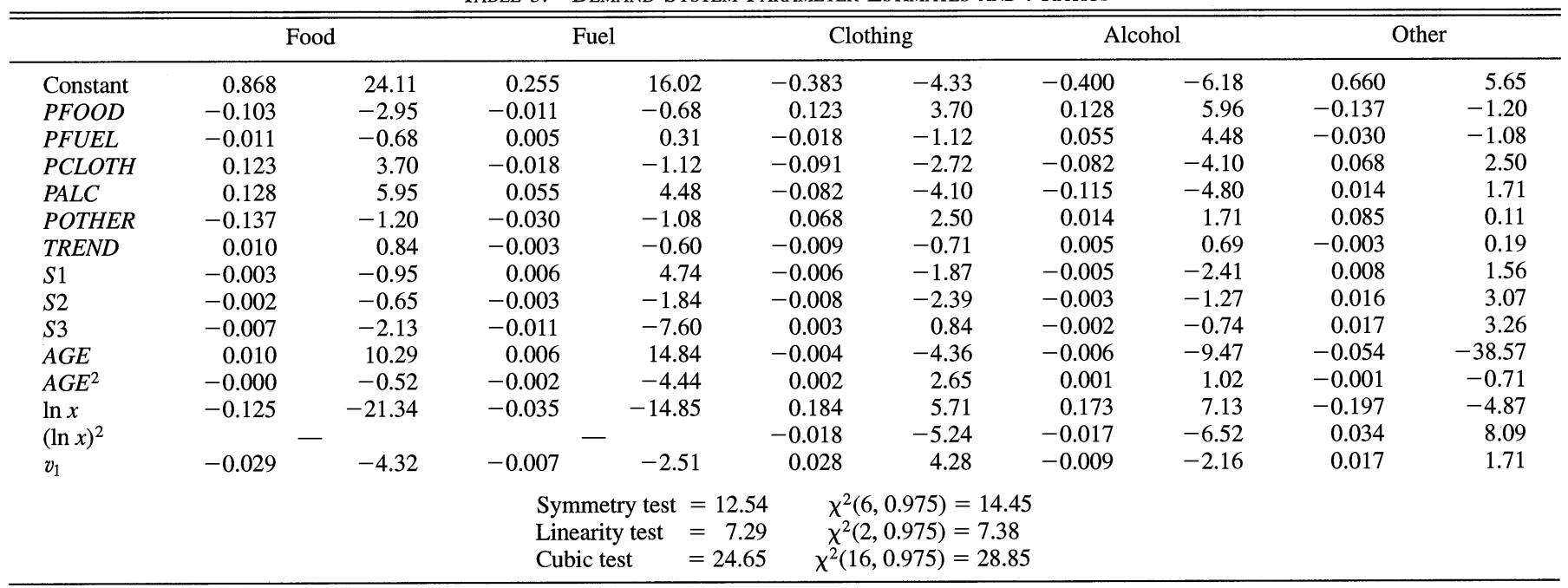

Notes: (1) All prices are in logarithms.

(2) Sample selection is married couples without children living in London and the South East.

(3) $\ln v_{1}$ is the (Wu-Hausman) reduced-form residual from the regression of $\ln x$ on the instrument set (see section II).

(4) The cubic test is a Wald test of the hypothesis that cubic terms in prices are jointly insignificant in the regression of the (unrestricted) residuals on RHS variables and higher order (cubed) price terms.

(5) The linearity test reports the test statistic for our restricted model with linear Engel curves for food and fuel against the alternative of quadratic Engel curves in all five commodity groups.

(6) Instruments for $\ln x$ in all equations were age and age squared of both adults, tenure, durable ownership dummies, interest rates, trend and higher order trend terms, smoker and white-collar dummies, prices (including durables and housing), normal household income and income squared, and interactions of prices and incomes.

rejected. ${ }^{9}$ Comparison of table 3 and table B. 2 in appendix B (which presents symmetry-restricted but not linearityrestricted results) reveals that the imposition of linearity for food and fuel does not seriously affect any other parameters in the system.

In figure 4 we present a nonparametric residual analysis with $95 \%$ confidence bands for our preferred specification for the food and alcohol equations under all the preference restrictions. If our specification is appropriate, this nonparametric regression should lie close to the horizontal axis. The estimates suggest that our QUAIDS AI specification of table 3 is not missing any serious systematic nonlinearities in the Engel curve. Similar patterns are observed in the residuals for the fuel, clothing, and "other" categories.

Finally, before moving to the welfare analysis of indirect tax reform, we report the elasticities in table 4 . These elasticities are calculated for each household individually, and then a weighted average is constructed, with the weights being equal to the household's share of total sample expenditure for the relevant good. Uncompensated ownprice elasticities are negative for all goods at all percentiles of the total expenditure distribution. In addition, we compute Slutsky matrices to examine concavity in the domain of our sample. The few violations we found were among the very highest spending households.

\section{Welfare Analysis and Indirect Tax Reform}

One of the main motivations for estimating demand systems is to facilitate welfare analysis. In what follows we use our estimated model to calculate some simple welfare

\footnotetext{
${ }^{9}$ In a smaller U.K. data set, Lewbel (1995) finds that the results of symmetry testing using the QUAIDS model agree with a fully nonparametric symmetry test.
}

measures for an example indirect tax reform. As a comparison model we use the popular AI model (in which all quadratic terms in $\ln x$ are omitted) estimated on the same data. The reform we consider is the imposition of a $17.5 \%$ sales tax on clothing. While this is certainly a large price change, it is not inconsistent with those price changes that would occur if a sales tax were added to a good not previously taxed. In the United Kingdom the current rate of value-added taxation (VAT) is $17.5 \%$, and children's clothing and footwear are among the goods that are not currently subject to this tax (although our "clothing" category includes adult clothing, which currently is subject to VAT). In a related paper we consider, for the same reform, how welfare analysis based on first- and second-order approximations to demand responses differs from that based on the full QUAIDS estimates (Banks et al. (1996)).

Using the parameters estimated above we can calculate indirect utilities from the functional form in equations (7)-(9), both before and after the reform. We plot the compensating variations, given by the difference in cost functions $c\left(\mathbf{p}^{1}, z, u^{0}\right)-c\left(\mathbf{p}^{0}, z, u^{0}\right)$ for each household in the final year of our data. These are positive for every point in our data, indicating that each household experiences a welfare loss as a result of the price rise. First we plot in figure 5 the welfare losses for the QUAIDS specification (in pounds per week) against the households' total expenditures. All households suffer positive utility losses, and these losses increase with total expenditure, as would be expected.

In figure 6 we indicate the "biases" obtained when the AI model is estimated on the same data. This figure plots the difference between the AI welfare loss and the QUAIDS welfare loss for each household as a proportion of that household's QUAIDS welfare loss. The figure shows that, 
Figure 4A.-A Residual ANALysis of The QUADRATIC SPECIFICATION FOR FOOD SHARES

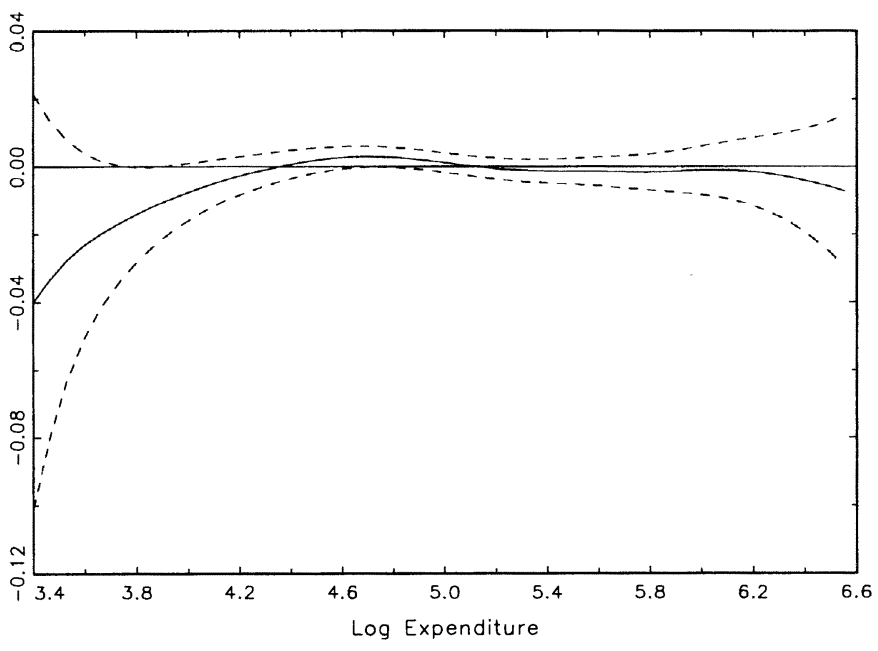

Figure 4B.-Residual Analysis of The Quadratic Specification for AlCOHOL SHARES

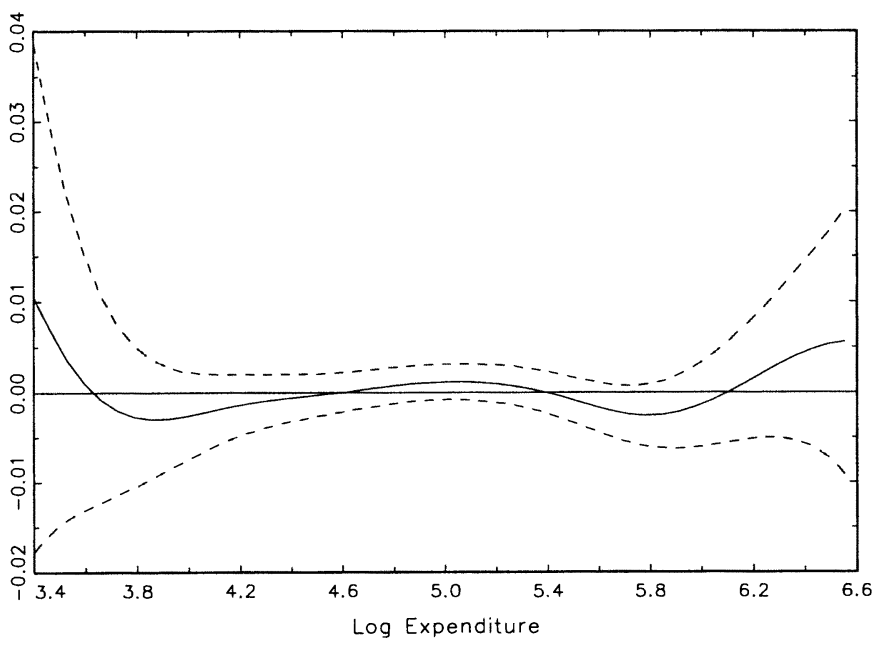

Figure 5.-Welfare Loss: QUAI Model, 17.5\% TAX on Clothing

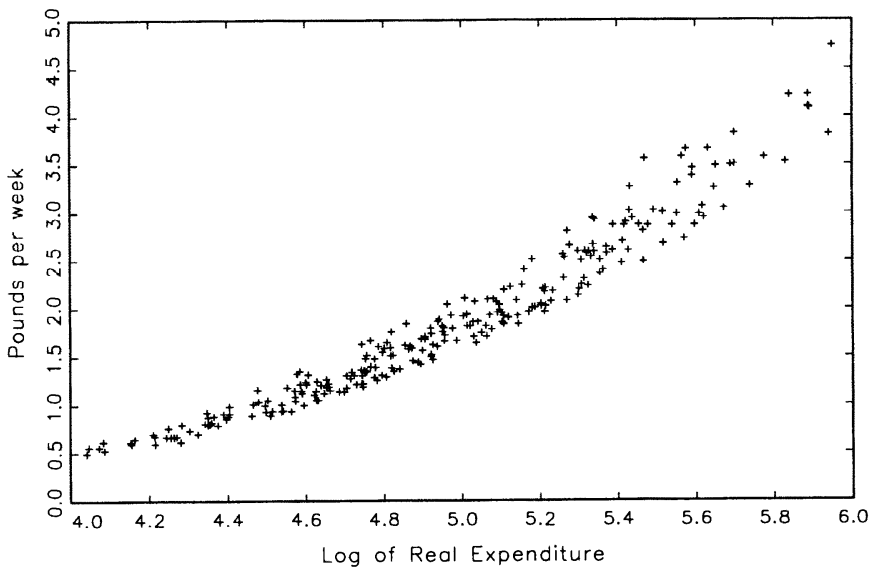

for this reform, the AI model understates the welfare losses for the majority of the distribution and overstates the welfare losses for the richer (and the very poorest) households, a result that is consistent with the AI model not allowing adequate curvature in the Engel curve for clothing. Indeed, looking at reforms to goods with linear Engel curves does not produce nearly such pronounced patterns.

\section{Summary and Conclusions}

This paper was motivated by the need to provide an accurate analysis of the welfare cost of indirect tax reform. Analyses of household budget surveys have pointed to more curvature in the Engel curve relationship than is permitted by the standard Working-Leser form. Our aim was to provide a detailed assessment of this result and to consider the appropriate form of preferences that support generalizations in the shape for the Engel curve relationship. This is

Table 4.-Estimated Demand Elasticities

\begin{tabular}{|c|c|c|c|c|c|}
\hline & Food & Fuel & Clothing & Alcohol & Other \\
\hline \multicolumn{6}{|c|}{ Compensated } \\
\hline Food & $-0.7817(0.15)$ & $0.1068(0.06)$ & $0.2919(0.13)$ & $0.2914(0.08)$ & $0.0888(0.11)$ \\
\hline Fuel & $0.4653(0.29)$ & $-0.7669(0.22)$ & $-0.4590(0.29)$ & $0.6330(0.19)$ & $0.1274(0.29)$ \\
\hline Clothing & $1.0423(0.41)$ & $-0.3805(0.17)$ & $-0.9606(0.42)$ & $0.0571(0.23)$ & $0.2419(0.34)$ \\
\hline Alcohol & $1.5341(0.42)$ & $0.7588(0.21)$ & $0.0580(0.41)$ & $-1.6492(0.44)$ & $-0.7017(0.59)$ \\
\hline Other & $0.0490(0.06)$ & $0.0163(0.03)$ & $0.0390(0.07)$ & $-0.0769(0.06)$ & $-0.0277(0.10)$ \\
\hline \multicolumn{6}{|c|}{ Uncompensated } \\
\hline Food & $-0.9593(0.16)$ & $0.0657(0.06)$ & $0.2474(0.13)$ & $0.2641(0.08)$ & $-0.1860(0.12)$ \\
\hline Fuel & $0.3130(0.31)$ & $-0.8040(0.21)$ & $-0.4946(0.29)$ & $0.6087(0.19)$ & $-0.0988(0.31)$ \\
\hline Clothing & $0.7129(0.44)$ & $-0.4546(0.17)$ & $-1.0535(0.41)$ & $-0.0075(0.23)$ & $-0.3358(0.39)$ \\
\hline Alcohol & $1.1543(0.44)$ & $0.6720(0.21)$ & $-0.0441(0.40)$ & $-1.7212(0.44)$ & $-1.3397(0.64)$ \\
\hline \multirow[t]{2}{*}{ Other } & $-0.3621(0.07)$ & $-0.0641(0.03)$ & $-0.0620(0.07)$ & $-0.1491(0.05)$ & $-0.6831(0.11)$ \\
\hline & Budget & Mean Shares & & & \\
\hline Food & $0.5680(0.11)$ & 0.2968 & & & \\
\hline Fuel & $0.4753(0.20)$ & 0.0675 & & & \\
\hline Clothing & $1.1388(0.38)$ & 0.0800 & & & \\
\hline Alcohol & $1.2786(0.38)$ & 0.0549 & & & \\
\hline Other & $1.2605(0.09)$ & 0.5007 & & & \\
\hline
\end{tabular}

Note: Standard errors are in parentheses. 
Figure 6.-Bias In Welfare Loss From Using the AI Model

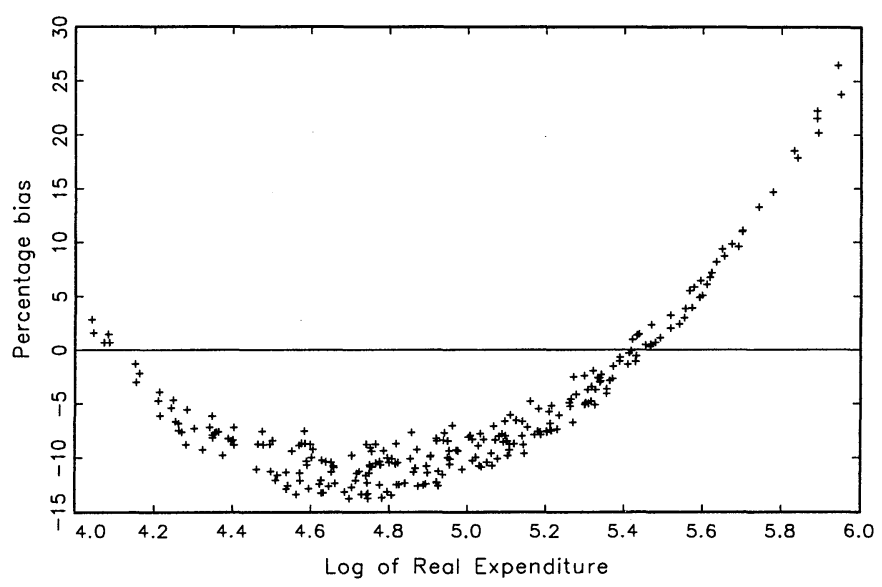

shown to be restricted to a class of quadratic logarithmic models. Given the importance of such models in understanding the impact of indirect tax reform, we consider the significance of our results in measuring the distribution of welfare gains for an indirect tax reform for the United Kingdom.

It seems clear that we can reject the linear Working-Leser form for certain commodity groups in the U.K. FES, although it is equally clear that for certain items, in particular food expenditures, linearity is unlikely to be rejected. Moreover, kernel regression analysis suggests that share equations quadratic in the logarithm of total expenditure provide a sufficiently general approximation to the Engel relationship in the raw microdata. In addition, models that require a constant ratio of linear to quadratic expenditure terms across commodity groups were also ruled out by our preliminary analysis.

We derive the unique class of quadratic Engel curve preferences that satisfy integrability without the requirement of the constant-ratio restriction. These demands are rank 3, which is the maximum possible rank for any demand system that is linear in functions of income. Furthermore it was shown that the coefficients of the quadratic term in these demands must be price dependent. This class nests the AI and the exactly aggregable translog models while allowing the flexibility of a rank 3 quadratic specification.

Using these results we specify the QUAIDS model, an empirical demand system that, with a minimum number of parameters and departures from linearity, possesses both price flexibility and the Engel curve shape observed in the data. The estimated model was found to produce a datacoherent and plausible description of consumer behavior from which we could calculate welfare measures associated with price and tax changes. These welfare measures show important divergences from similar measures calculated for a standard model that is linear in log expenditure, reflecting the importance of including quadratic expenditure terms to account for goods being luxuries at some income levels and necessities at others.
The use of semiparametric or nonparametric methods as an alternative solution to this problem will often be impractical. Kernel-based methods are not amenable to having Slutsky symmetry imposed on them. Series-based semiparametric models have numbers of parameters that increase explosively with the number of terms in the expansion, and restrictions on homogeneity and Slutsky symmetry prevent adding income parameters without also adding price parameters. Finally, nonparametric analyses of Engel curves and of residuals from the parametric QUAIDS model indicate that the QUAIDS is adequate, so no additional semiparametric terms are required. However, if desired in contexts having substantially more than the usual amount of price variation, expansion terms could be appended to the QUAIDS specification.

Our results indicate that studies based on AI or translog preferences will badly misspecify the distribution of welfare losses by failing to model Engel curvature correctly. The empirical findings on the shape of Engel curves also show that welfare calculations based on Engel or Rothbarth scales must be invalid, since such scales require that Engel curves be monotonic in utility, and hence in total expenditures. For example, many Rothbarth scales use expenditures on alcohol or clothing to measure welfare. Our empirical findings indicate that rich or poor households alike may have equal expenditures or budget shares on these goods.

\section{REFERENCES}

Atkinson, A. B., J. Gomulka, and N. H. Stern, "Spending on Alcohol: Evidence from the Family Expenditure Survey 1970-1983," Economic Journal 100 (1990), 808-827.

Banks, J. W., R. W. Blundell, and A. Lewbel, "Tax Reform and Welfare Measurement: Do We Need Demand System Estimation?" Economic Journal 106 (1996), 1227-1241.

Barnett, W. A., and A. Jonas, "The Muntz-Szatz Demand System: An Application of a Globally Well Behaved Series Expansion," Economics Letters 11 (1983), 337-342.

Bierens, H. J., and H. A. Pott-Buter, "Specification of Household Engel Curves by Nonparametric Regression," Econometric Reviews 9 (1987), 123-184.

Blundell, R. W., "Consumer Behaviour: Theory and Empirical Evidence," Economic Journal 98 (1988), 16-65.

Blundell, R. W., P. Pashardes, and G. Weber, "What Do We Learn about Consumer Demand Patterns from Micro-Data?," American Economic Review 83 (1993), 570-597.

Blundell, R. W., and J. M. Robin, "An Iterated Moment Estimated for Conditionally Linear Demand Systems," Institute for Fiscal Studies, Working Paper 96/10 (1996).

Browning, M. J., and C. Meghir, "The Effects of Male and Female Labour Supply on Commodity Demands," Econometrica 59 (1991), 925951.

Cooper, R. J., and K. R. McLaren, "A System of Demand Equations Satisfying Effectively Global Regularity Conditions," this REvIEw 78 (May 1996), 359-364

Cragg, J. G., and S. G. Donald, "Inferring the Rank of a Matrix," mimeo, University of British Columbia, Journal of Econometrics (1995).

Deaton, A. S., "A Reconsideration of the Empirical Implications of Additive Preferences," Economic Journal 84 (1974), 338-348.

Deaton, A. S., and J. Muellbauer, "An Almost Ideal Demand System," American Economic Review 70 (1980), 312-336.

" "On Measuring Child Costs: With Applications to Poor Countries," Journal of Political Economy 94 (1986), 720-744.

Duncan, A. S., and A. S. Jones, "NP-REG: An Interactive Package for Kernel Density Estimation and Non-Parametric Regression," IFS Working Paper W92/07 (1992). 
Engel, E., "Die Lebenskosten belgischer Arbeiter-Familien früher and jetzt," International Statistical Institute Bulletin 9 (1895), 1-74.

Gill, L., and A. Lewbel, "Testing the Rank of Estimated Matrices with Applications to Factor, State Space, and ARMA Models," Journal of the American Statistical Association 87 (Sept. 1992), 766-776.

Gallant, R. A., and G. Souza, "On the Asymptotic Normality of Fourier Flexible Form Estimates," Journal of Econometrics 30 (1991), 329-353.

Gorman, W. M., "Some Engel Curves," in The Theory and Measurement of Consumer Behaviour, Angus Deaton (ed.) (Cambridge, UK: Cambridge University Press, 1981).

Härdle, W., Applied Nonparametric Regression (Cambridge, UK: Cambridge University Press, 1990).

Härdle, W., and M. Jerison, "The Evolution of Engel Curves over Time," discussion paper A-178, SFB 303, University of Bonn (1988).

Hausman, J. A., W. K. Newey, and J. L. Powell, "Nonlinear Errors in Variables: Estimation of Some Engel Curves," Journal of Econometrics 65 (1995), 205-233.

Hildenbrand, W., Market Demand: Theory and Empirical Evidence (Princeton, NJ: Princeton University Press, 1994).

Holly, A., “A Remark on Hausman's Specification Test," Econometrica 50 (1982), 749-759.

Howe, H., R. A. Pollak, and T. J. Wales, "Theory and Time Series Estimation of the Quadratic Expenditure System," Econometrica 47 (1979), 1231-1248.

Jorgenson, D. W., L. J. Lau, and T. M. Stoker, "The Transcendental Logarithmic Model of Aggregate Consumer Behavior," in R. Basmann and G. Rhodes (eds.), Advances in Econometrics, vol. 1 (Greenwich, Ct: JAI Press, 1982).

Leser, C. E. V., "Forms of Engel Functions," Econometrica 31 (1963), 694-703.

Lewbel, A., "Full Rank Demand Systems," International Economic Review 31 (1990), 289-300.

"The Rank of Demand Systems: Theory and Nonparametric Estimation," Econometrica 59 (1991), 711-730.

"Consistent Non-Parametric Hypothesis Tests with an Application to Slutsky Symmetry," Journal of Econometrics 67 (1995), 379401.
Muellbauer, J., "Community Preferences and the Representative Consumer," Econometrica 44 (1976), 525-543.

van Daal, J., and A. H. Q. M. Merkies, "A Note on the Quadratic Expenditure System," Econometrica 57 (1989), 1439-1443.

Working, H., "Statistical Laws of Family Expenditure," Journal of the American Statistical Association 38 (1943), 43-56.

\section{APPENDIX A}

Proof of Theorem 1

The demand system in equation (1) has three terms, so its maximum rank is 3. If equation (1) has rank 1 , it must be homothetic, so $B_{i}(\mathbf{p})=$ $C_{i}(\mathbf{p})=0$. If equation (1) has rank 2 , the indirect utility function must have the form $V=h[\ln b(\mathbf{p}), \ln x]$ with $x=m / a(\mathbf{p})$ for some $a(\mathbf{p})$ and $b(\mathbf{p})$ (Gorman (1981)). By Roy's identity we can write

$$
\begin{gathered}
w_{i}=H(b(\mathbf{p}), x) \frac{\partial \ln b(\mathbf{p})}{\partial \ln p_{i}}+\frac{\partial \ln a(\mathbf{p})}{\partial \ln p_{i}}, \\
\text { where } \quad H=\frac{-[\partial h / \partial \ln b(\mathbf{p})]}{\partial h / \partial \ln x} .
\end{gathered}
$$

Equation (1) can be written in the form of equation (A.1) if and only if $H(b, x)=H_{1}(b)+H_{2}(b) \ln x+H_{3}(b) g(x)$, making $B_{i}=H_{2}(b)[\partial \ln$ $\left.b / \partial \ln p_{i}\right]$ and $C_{i}=H_{3}(b)\left[\partial \ln b / \partial \ln p_{i}\right]$, so $C_{i} / B_{i}=H_{2} / H_{3} \equiv d(\mathbf{p})$. Finally, if equation (1) has rank 3 , then applying Lewbel's (1990) characterization of full rank demand systems shows that the only rank 3 system that is linear in $\ln m$ and any other function of $\ln m$ is the quadratic logarithmic, which has the indirect utility function $V=\eta\left\{\left[\theta_{1}(p)+\theta_{2}(p) \ln m\right]^{-1}+\theta_{3}(p)\right\}$ for some monotonic function $\eta$. The proof then follows immediately from equation (A.1), which is from Muellbauer's (1976) characterization of PIGLOG demands.

\section{APPENDIX B}

TABle B.1.-UnRestricted Estimates of QUAI Model

\begin{tabular}{lrrrr}
\hline \hline & \multicolumn{1}{c}{ Food } & \multicolumn{1}{c}{ Fuel } & Clothing & Alcohol \\
\hline INTERCEP & $1.18634(0.1073)$ & $0.25747(0.0426)$ & $-0.43553(0.1049)$ & $-0.39579(0.0708)$ \\
PFOOD & $-0.20752(0.0582)$ & $0.00671(0.0231)$ & $0.05660(0.0569)$ & $0.10548(0.0384)$ \\
PFUEL & $-0.05564(0.0407)$ & $-0.00328(0.0162)$ & $0.01605(0.0398)$ & $0.06259(0.0268)$ \\
PCLOTH & $0.20247(0.0550)$ & $-0.03374(0.0219)$ & $-0.04032(0.0538)$ & $-0.05403(0.0363)$ \\
PALC & $0.16169(0.0395)$ & $0.06263(0.0157)$ & $-0.16410(0.0386)$ & $-0.10969(0.0261)$ \\
TREND & $0.00860(0.0166)$ & $-0.00673(0.0066)$ & $-0.00277(0.0163)$ & $-0.01438(0.0110)$ \\
SPRING & $-0.00292(0.0034)$ & $0.00624(0.0013)$ & $-0.00528(0.0033)$ & $-0.00530(0.0022)$ \\
SUMMER & $-0.00215(0.0034)$ & $-0.00245(0.0014)$ & $-0.00822(0.0034)$ & $-0.00292(0.0023)$ \\
AUTUMN & $-0.00725(0.0036)$ & $-0.01027(0.0014)$ & $0.00171(0.0035)$ & $-0.00215(0.0023)$ \\
AGE & $0.00972(0.0010)$ & $0.00564(0.0004)$ & $-0.00402(0.0009)$ & $-0.00598(0.0006)$ \\
AGE & $-0.00055(0.0009)$ & $-0.00165(0.0004)$ & $0.00246(0.0009)$ & $0.00062(0.0006)$ \\
$\ln x$ & $-0.25719(0.0419)$ & $-0.03351(0.0167)$ & $0.19981(0.0410)$ & $0.16438(0.0277)$ \\
$\ln x^{2}$ & $0.01368(0.0043)$ & $-0.00011(0.0017)$ & $-0.01942(0.0042)$ & $-0.01562(0.0029)$ \\
$v_{1}$ & $-0.02795(0.0067)$ & $-0.00698(0.0027)$ & $0.02765(0.0066)$ & $-0.00930(0.0044)$ \\
\hline
\end{tabular}

Notes: (1) Standard errors are in parentheses.

(2) Instruments in all equations were age and age squared of both adults, tenure, durable ownership dummies, interest rates, trend and higher order trend terms, smoker and white collar dummies, prices (including durables and housing), normal household income and income squared, and interactions of prices and incomes.

Table B.2.-Symmetry Restricted Minimum-Distance Estimates

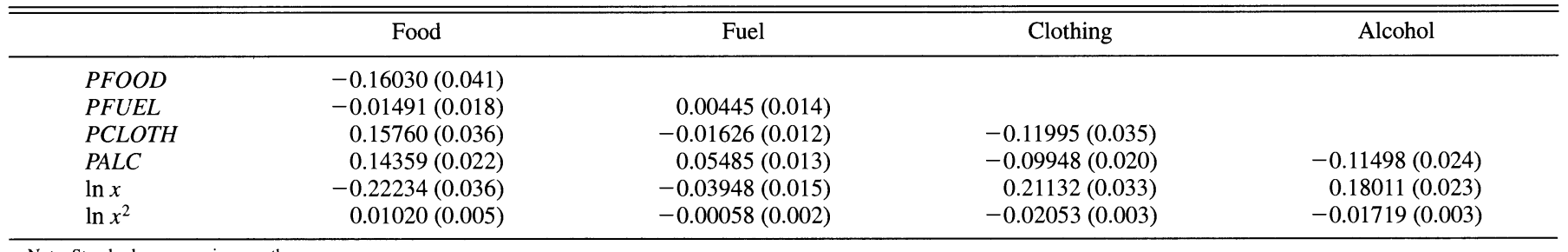


TABLE B.3.-UnRestricted Estimates For Almost IDEAL MODEL

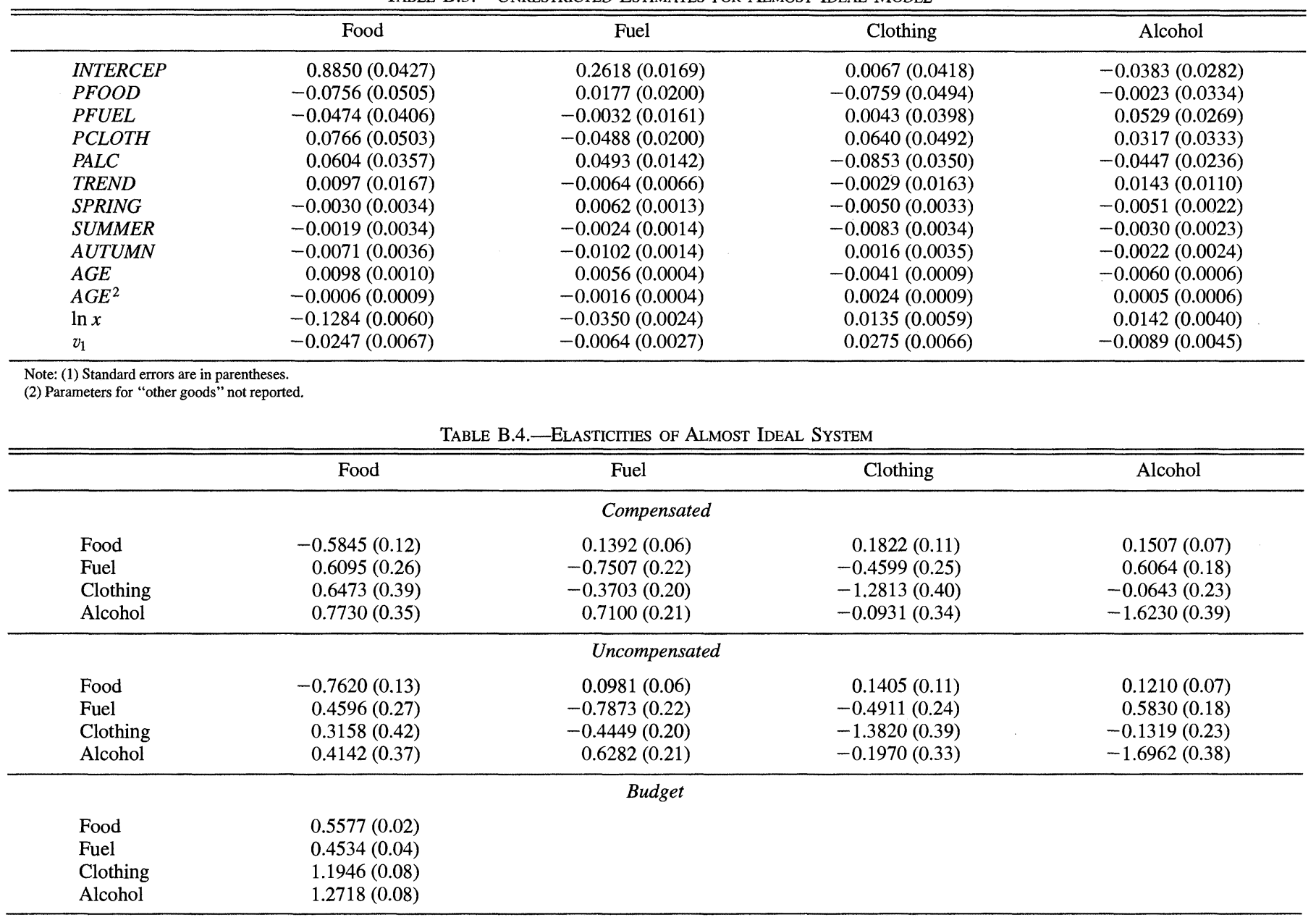

Notes: (1) Standard errors are in parentheses.

(2) Parameters for "other goods" not reported. 
http://www.jstor.org

\title{
LINKED CITATIONS
}

- Page 1 of 4 -

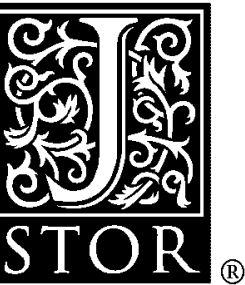

You have printed the following article:

\section{Quadratic Engel Curves and Consumer Demand}

James Banks; Richard Blundell; Arthur Lewbel

The Review of Economics and Statistics, Vol. 79, No. 4. (Nov., 1997), pp. 527-539.

Stable URL:

http://links.jstor.org/sici?sici=0034-6535\%28199711\%2979\%3A4\%3C527\%3AQECACD\%3E2.0.CO\%3B2-Z

This article references the following linked citations. If you are trying to access articles from an off-campus location, you may be required to first logon via your library web site to access JSTOR. Please visit your library's website or contact a librarian to learn about options for remote access to JSTOR.

\section{[Footnotes]}

\author{
${ }^{2}$ What do we Learn About Consumer Demand Patterns from Micro Data? \\ Richard Blundell; Panos Pashardes; Guglielmo Weber \\ The American Economic Review, Vol. 83, No. 3. (Jun., 1993), pp. 570-597. \\ Stable URL: \\ http://links.jstor.org/sici?sici=0002-8282\%28199306\%2983\%3A3\%3C570\%3AWDWLAC\%3E2.0.CO\%3B2-9 \\ ${ }^{8}$ An Almost Ideal Demand System \\ Angus Deaton; John Muellbauer \\ The American Economic Review, Vol. 70, No. 3. (Jun., 1980), pp. 312-326. \\ Stable URL: \\ http://links.jstor.org/sici?sici=0002-8282\%28198006\%2970\%3A3\%3C312\%3AAAIDS\%3E2.0.CO\%3B2-Q
}

\section{References}

Spending on Alcohol: Evidence from the Family Expenditure Survey 1970-1983

A. B. Atkinson; J. Gomulka; N. H. Stern

The Economic Journal, Vol. 100, No. 402. (Sep., 1990), pp. 808-827.

Stable URL:

http://links.jstor.org/sici?sici=0013-0133\%28199009\%29100\%3A402\%3C808\%3ASOAEFT\%3E2.0.CO\%3B2-I

NOTE: The reference numbering from the original has been maintained in this citation list. 
http://www.jstor.org

\section{LINKED CITATIONS}

- Page 2 of 4 -

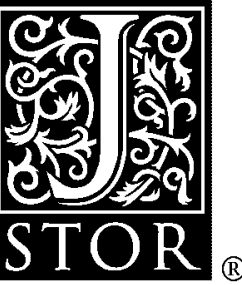

Tax Reform and Welfare Measurement: Do We Need Demand System Estimation?

James Banks; Richard Blundell; Arthur Lewbel

The Economic Journal, Vol. 106, No. 438. (Sep., 1996), pp. 1227-1241.

Stable URL:

http://links.jstor.org/sici?sici=0013-0133\%28199609\%29106\%3A438\%3C1227\%3ATRAWMD\%3E2.0.CO\%3B2-9

Consumer Behaviour: Theory and Empirical Evidence--A Survey

Richard Blundell

The Economic Journal, Vol. 98, No. 389. (Mar., 1988), pp. 16-65.

Stable URL:

http://links.jstor.org/sici?sici=0013-0133\%28198803\%2998\%3A389\%3C16\%3ACBTAEE\%3E2.0.CO\%3B2-9

\section{What do we Learn About Consumer Demand Patterns from Micro Data?}

Richard Blundell; Panos Pashardes; Guglielmo Weber

The American Economic Review, Vol. 83, No. 3. (Jun., 1993), pp. 570-597.

Stable URL:

http://links.jstor.org/sici?sici=0002-8282\%28199306\%2983\%3A3\%3C570\%3AWDWLAC\%3E2.0.CO\%3B2-9

\section{The Effects of Male and Female Labor Supply on Commodity Demands}

Martin Browning; Costas Meghir

Econometrica, Vol. 59, No. 4. (Jul., 1991), pp. 925-951.

Stable URL:

http://links.jstor.org/sici?sici=0012-9682\%28199107\%2959\%3A4\%3C925\%3ATEOMAF\%3E2.0.CO\%3B2-8

\section{Review: [Untitled]}

Reviewed Work(s):

Permanent Income, Wealth, and Consumption. by Thomas Mayer

Angus Deaton

The Economic Journal, Vol. 84, No. 333. (Mar., 1974), pp. 200-202.

Stable URL:

http://links.jstor.org/sici?sici=0013-0133\%28197403\%2984\%3A333\%3C200\%3APIWAC\%3E2.0.CO\%3B2-F

\section{An Almost Ideal Demand System}

Angus Deaton; John Muellbauer

The American Economic Review, Vol. 70, No. 3. (Jun., 1980), pp. 312-326.

Stable URL:

http://links.jstor.org/sici?sici=0002-8282\%28198006\%2970\%3A3\%3C312\%3AAAIDS\%3E2.0.CO\%3B2-Q

NOTE: The reference numbering from the original has been maintained in this citation list. 
http://www.jstor.org

\section{LINKED CITATIONS}

- Page 3 of 4 -

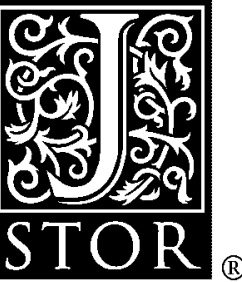

\section{On Measuring Child Costs: With Applications to Poor Countries}

Angus S. Deaton; John Muellbauer

The Journal of Political Economy, Vol. 94, No. 4. (Aug., 1986), pp. 720-744.

Stable URL:

http://links.jstor.org/sici?sici=0022-3808\%28198608\%2994\%3A4\%3C720\%3AOMCCWA\%3E2.0.CO\%3B2-3

Testing the Rank and Definiteness of Estimated Matrices With Applications to Factor, State-Space and ARMA Models

Len Gill; Arthur Lewbel

Journal of the American Statistical Association, Vol. 87, No. 419. (Sep., 1992), pp. 766-776.

Stable URL:

http://links.jstor.org/sici?sici=0162-1459\%28199209\%2987\%3A419\%3C766\%3ATTRADO\%3E2.0.CO\%3B2-L

\section{A Remark on Hausman's Specification Test}

Alberto Holly

Econometrica, Vol. 50, No. 3. (May, 1982), pp. 749-759.

Stable URL:

http://links.jstor.org/sici?sici=0012-9682\%28198205\%2950\%3A3\%3C749\%3AAROHST\%3E2.0.CO\%3B2-N

\section{Theory and Time Series Estimation of the Quadratic Expenditure System}

Howard Howe; Robert A. Pollak; Terence J. Wales

Econometrica, Vol. 47, No. 5. (Sep., 1979), pp. 1231-1247.

Stable URL:

http://links.jstor.org/sici?sici=0012-9682\%28197909\%2947\%3A5\%3C1231\%3ATATSEO\%3E2.0.CO\%3B2-O

\section{Forms of Engel Functions}

C. E. V. Leser

Econometrica, Vol. 31, No. 4. (Oct., 1963), pp. 694-703.

Stable URL:

http://links.jstor.org/sici?sici=0012-9682\%28196310\%2931\%3A4\%3C694\%3AFOEF\%3E2.0.CO\%3B2-I

\section{Full Rank Demand Systems}

Arthur Lewbel

International Economic Review, Vol. 31, No. 2. (May, 1990), pp. 289-300.

Stable URL:

http://links.jstor.org/sici?sici=0020-6598\%28199005\%2931\%3A2\%3C289\%3AFRDS\%3E2.0.CO\%3B2-A

NOTE: The reference numbering from the original has been maintained in this citation list. 
http://www.jstor.org

\title{
LINKED CITATIONS \\ - Page 4 of 4 -
}

The Rank of Demand Systems: Theory and Nonparametric Estimation

Arthur Lewbel

Econometrica, Vol. 59, No. 3. (May, 1991), pp. 711-730.

Stable URL:

http://links.jstor.org/sici?sici=0012-9682\%28199105\%2959\%3A3\%3C711\%3ATRODST\%3E2.0.CO\%3B2-Q

Community Preferences and the Representative Consumer

John Muellbauer

Econometrica, Vol. 44, No. 5. (Sep., 1976), pp. 979-999.

Stable URL:

http://links.jstor.org/sici?sici=0012-9682\%28197609\%2944\%3A5\%3C979\%3ACPATRC\%3E2.0.CO\%3B2-K

\author{
A Note on the Quadratic Expenditure Model \\ Jan Van Daal; Arnold H. Q. M. Merkies \\ Econometrica, Vol. 57, No. 6. (Nov., 1989), pp. 1439-1443. \\ Stable URL: \\ http://links.jstor.org/sici?sici=0012-9682\%28198911\%2957\%3A6\%3C1439\%3AANOTQE\%3E2.0.CO\%3B2-C

\section{Statistical Laws of Family Expenditure} \\ Holbrook Working \\ Journal of the American Statistical Association, Vol. 38, No. 221. (Mar., 1943), pp. 43-56. \\ Stable URL: \\ http://links.jstor.org/sici?sici=0162-1459\%28194303\%2938\%3A221\%3C43\%3ASLOFE\%3E2.0.CO\%3B2-S
}

NOTE: The reference numbering from the original has been maintained in this citation list. 